\title{
Diagnosis of congenital heart malformations - possibilities for the employment of telepathology
}

\author{
Cornelia Tennstedt ${ }^{\mathrm{a}, *}$, Kathrin Sunkel-Wehrstedt ${ }^{\mathrm{b}}$, \\ Martin Vogel ${ }^{\mathrm{c}}$ and Peter Hufnagl ${ }^{\mathrm{d}}$ \\ ${ }^{a}$ Department of Pathology, Charité, Medical Faculty \\ of the Humboldt University, Berlin, Germany \\ ${ }^{\mathrm{b}}$ Department of Pathology, Charité, Medical Faculty \\ of the Humboldt University, Berlin, Germany \\ ${ }^{\mathrm{c}}$ Unit of Paediatric Pathology and Placentology, \\ Department of Pathology, Charité, Medical Faculty of \\ the Humboldt University, Berlin, Germany \\ ${ }^{\mathrm{d}}$ Department of Pathology, Charité, Medical Faculty \\ of the Humboldt University, Berlin, Germany
}

Goal: In a study of 10 autopsy cases with congenital cardiac malformations we investigated whether obtaining a second opinion by means of telepathology could satisfy quality standards for the diagnosis of cardiac malformations and what the advantages and disadvantages of such a procedure might be. Material: The investigatory samples were 10 formalinfixed hearts with complex malformations from 9 fetuses and one newborn on which autopsies had been performed at the Pathological Institute of the Charité Hospital. The requests for a second opinion, which included text and image data, were sent in the form of Microsoft PowerPoint presentations to 5 experts in 4 countries. Per case the number of images that were sent was between 3 and 7. The size of the files was between 439 and $942 \mathrm{~kb}$. The time required for preparation of the cases for sending them to the specialists was between 1 and 2 hours: this encompassed the time for putting the notation on the images, compressing them, creating a file that included both the images and the clinical data and then sending the case file. Results: All 10 cardiac malformations were correctly identified. In 8 of the 10 cases at least one expert had questions. After these questions had been answered and further images had been sent final correct diagnoses were made in all cases. All experts said that the quality of the images was very good. Use of a standardized findings questionnaire,

\footnotetext{
*Corresponding author: Cornelia Tennstedt, MD, Department of Pathology, Charité, Medical Faculty of the Humboldt University, D-10098 Berlin, Germany. Tel.: +49 302802 2730; Fax: +49 30 2802 5668; E-mail: cornelia.tennstedt@ charite.de.
}

which also included the marking of anatomic structures and of pathological findings in the images, proved useful. Standardized findings forms facilitate orientation during interpretation of the cases and should be used generally to avoid misunderstandings in telepathological communication. Conclusions: In general it is possible to obtain an effective and reliable diagnosis of congenital heart malformations by means of telepathology. It is far quicker to get a second opinion by this means than by conventional means.

Keywords: Congenital cardiac malformation, post-mortem examination, telepathology, second opinion

\section{Introduction}

The enormous progress made in ultrasound technology in recent years, as well as the diagnostic and therapeutic procedures this has made possible, have also led to considerable changes in the clinical view of the autopsy of fetuses. Because of the relatively large number of fetuses and newborns with cardiac malformations requiring postmortem examination at the Institute for Pathology of Charité Hospital (about 30-40 per year) and the large spectrum of these disorders, diagnosis of heart malformations has come to play a significant role in the work of the institute.

Since complex heart malformations are difficult to diagnose, it is of use in individual cases to obtain a second opinion from specialists in the field. Traditionally this has meant either that an experienced pathologist participates in the actual heart dissection in the autopsy room or that the heart has to be sent fixed in formalin to the expert by conventional mail. In contrast with this it is possible, by using telepathology, to present a live demonstration of the heart findings during the autopsy (online) or to send static images and accompanying information at a later point in time (offline).

The goal of the present study was to show how telepathology offline can be used to obtain a second opinion for the diagnosis of congenital heart malformations. 


\section{Materials and methods}

\subsection{Cases}

The material for the present investigation comprised 10 formalin-fixed hearts with various complex malformations. The hearts came from 9 fetuses between the 21 st and 24th week of gestation and one 3-day old newborn, all of whom had been presented for autopsy at the Institute of Pathology of the Charité Hospital (Table 1).

\subsection{Making of the images}

The pathologic findings in the heart cases were obtained as stereomicroscopic JPEG-compressed digital images (JPEG compression with Photoshop, compression rate $1: 2$ ) and prepared as PowerPoint presenta- tions with additional text data. The system TPS Version 1.5 was used for this which was developed as a cooperative effort between the Charité and Leica Microsystems (Copyright Leica Microsystems Wetzlar GmbH, Charité Berlin 1998-2000) [3]. The telepathology system TPS enables the investigator to save pictures taken during the autopsy in a case-based database, so that they can be sent later to an expert for a second opinion via email.

The telepathology system in the laboratory for fetal autopsy consists of a PC (Pentium II) with a webcam, microphone and speaker, a stereomicroscope (Olympus SZH 10, Olympus Co., Japan; 3CCD video camera Sony DXC 930p, Sony Corporation, Japan) and a macroscope (VZ 15b, Wolfvision GmbH, Austria) (Fig. 1).

Table 1

List of cases with cardiovascular malformations

\begin{tabular}{|c|c|c|c|c|}
\hline Case No. & Cardiovascular malformations & $\begin{array}{l}\text { Extracardial } \\
\text { malformations }\end{array}$ & $\begin{array}{l}\text { Chromosome } \\
\text { anomalies }\end{array}$ & $\begin{array}{c}\text { Weeks of gestation/ } \\
\text { age }\end{array}$ \\
\hline 1 & $\begin{array}{l}\text { Interruption of aortic arch ("Type B"), } \\
\text { double commited and juxtaarterial ventricular septal defect }\end{array}$ & $\begin{array}{l}\text { Thymus aplasia, } \\
\text { dysmorphic signs }\end{array}$ & $\begin{array}{l}\text { Microdeletion } \\
22 \mathrm{q} 11.2\end{array}$ & 22 \\
\hline 2 & $\begin{array}{l}\text { Common atrioventricular junction (Rastelli Type a), } \\
\text { defect within oval fossa (atrial septum defect II) }\end{array}$ & Dysmorphic signs & $47, X Y,+21$ & 23 \\
\hline 3 & $\begin{array}{l}\text { Double outlet right ventricle, } \\
\text { discordant atrioventricular connections, } \\
\text { subpulmonary perimembranous ventricular septal defect, } \\
\text { slit-like muscular ventricular septal defect }\end{array}$ & None & None & 22 \\
\hline 4 & $\begin{array}{l}\text { Double outlet right ventricle, } \\
\text { subpulmonary perimembranous ventricular septal defect }\end{array}$ & Dysmorphic signs & $47, \mathrm{XY},+18$ & 24 \\
\hline 5 & $\begin{array}{l}\text { Complete transposition of the great arteries, } \\
\text { concordant atrioventricular and discordant ventriculoarterial } \\
\text { connections, small perimembranous ventricular septal defect }\end{array}$ & None & None & 22 \\
\hline 6 & $\begin{array}{l}\text { Tetralogy of Fallot } \\
\text { with "absent pulmonary valve syndrome“, } \\
\text { absence of arterial duct, right aortic arch, } \\
\text { perimembranous ventricular septal defect }\end{array}$ & $\begin{array}{l}\text { Thymus aplasia, } \\
\text { dysmorphic signs }\end{array}$ & $\begin{array}{l}\text { Microdeletion } \\
22 \mathrm{q} 11.2\end{array}$ & 21 \\
\hline 7 & $\begin{array}{l}\text { Complete transposition of the great arteries } \\
\text { with pulmonary atresia, } \\
\text { concordant atrioventricular and discordant } \\
\text { ventriculoarterial connections, perimembranous } \\
\text { ventricular septal defect }\end{array}$ & $\begin{array}{l}\text { Dysmorphic signs, } \\
\text { lung hypoplasia, } \\
\text { cleft lip and palate }\end{array}$ & $47, X Y,+13$ & 22 \\
\hline 8 & $\begin{array}{l}\text { Hypoplastic left heart syndrome, } \\
\text { aortic atresia, mitral stenosis with dysplastic valve }\end{array}$ & None & None & 22 \\
\hline 9 & $\begin{array}{l}\text { Hypoplastic left heart syndrome, } \\
\text { aortic atresia, mitral stenosis, left ventricular fibroelastosis }\end{array}$ & None & None & $\begin{array}{l}\text { Live born } \\
3 \text { days old }\end{array}$ \\
\hline 10 & $\begin{array}{l}\text { Aortic valve stenosis, } \\
\text { dilated left ventricle, primary left ventricular fibroelastosis }\end{array}$ & None & None & 22 \\
\hline
\end{tabular}




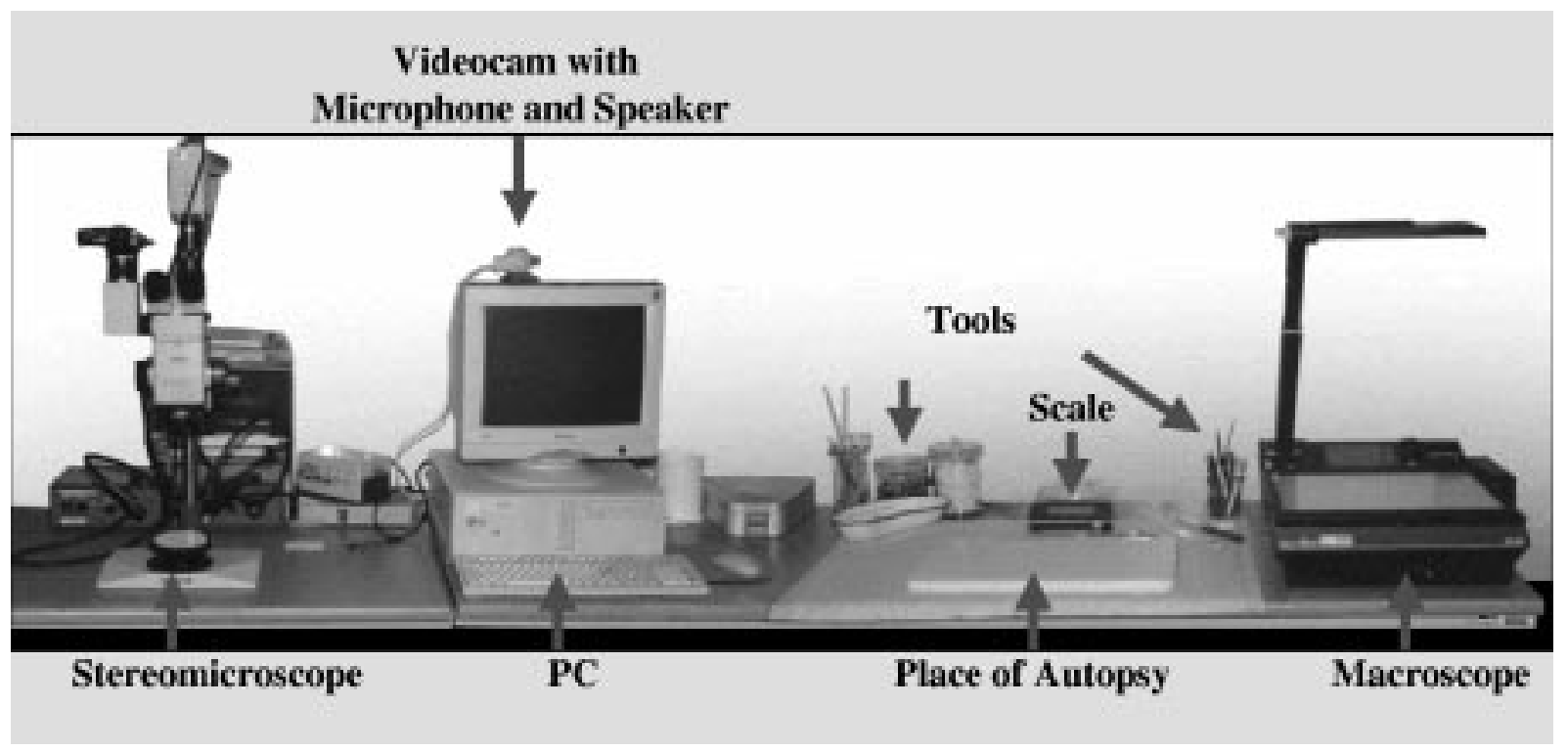

Fig. 1. The fetal autopsy laboratory with the technical equipment.

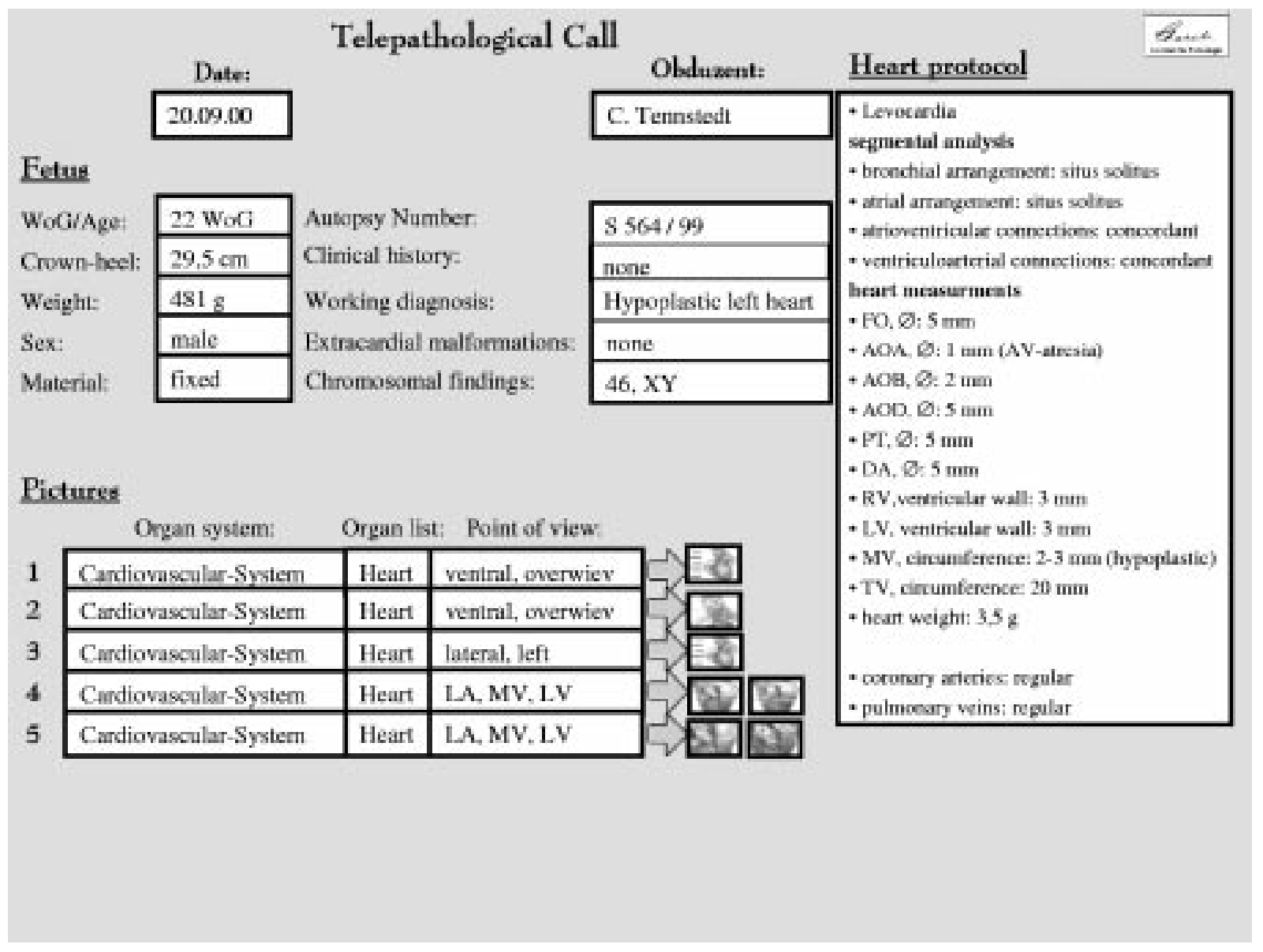

Fig. 2. PowerPoint presentation of a telepathologic case. 


\subsection{Structure of the case request}

Special masks in PowerPoint were developed for sending the various cardiac cases to the specialists for a second opinion.

The PowerPoint presentation is structured as follows:

(1) data of the submitter and the receiver,

(2) general data about the case, special cardiac data (Fig. 2a),

(3) organ system and organ, image of the malformation with identifying abbreviations and scale (Fig. 2b),

(4) working diagnosis and question(s),

(5) text fields for the second opinion, differential diagnoses and any questions the expert might have.

\subsection{Orientation in the images}

At the start of the series of images a general overview of the heart is given and a dimension scale included. The anatomic heart and vessel structures, as well as the pathological findings, are accompanied by identifying abbreviations.

In the Appendix to the case presentation there is a list of abbreviations for the anatomy of the heart and for the pathomorphologic terminology of cardiac malformations (Table 2), which serves as the basis for an unambiguous identification in the images.

\subsection{Study design}

In addition, user instructions for working with the case presentations as well as a questionnaire for the expert to fill out were sent. In the questionnaire the quality of the images, the comprehensibility of the case file, the ease of use and the general satisfaction with the structure of the case request were to be evaluated. The time spent in preparation per case was about 1-2

Table 2

List of abbreviations

\begin{tabular}{ll}
\hline Abbreviation & Term \\
\hline Heart anatomy & \\
AV & Aortic valve \\
AO & Aorta \\
AOA & Ascending aorta \\
AOB & Aortic arch \\
DA & Arterial duct \\
\hline
\end{tabular}

Table 2

(Continued)

\begin{tabular}{|c|c|}
\hline Abbreviation & Term \\
\hline$\overline{\mathrm{DAO}}$ & Descending aorta \\
\hline FO & Oval foramen \\
\hline IVS & Interventricular septum \\
\hline LA & Left atrium \\
\hline LAP & Left atrial appendage \\
\hline LCA & Left coronary artery \\
\hline LCCA & Left common carotid artery \\
\hline LPA & Left pulmonary artery \\
\hline LSA & Left subclavian artery \\
\hline LV & Left ventricle \\
\hline $\mathrm{MeS}$ & Membranous septum \\
\hline MuS & Muscular septum \\
\hline MV & Mitral valve \\
\hline PT & Pulmonary trunk \\
\hline PV & Pulmonary valve \\
\hline RA & Right atrium \\
\hline RAP & Right atrial appendage \\
\hline $\mathrm{RCA}$ & Right coronary artery \\
\hline RCCA & Right common carotid artery \\
\hline RPA & Right pulmonary artery \\
\hline RSA & Right subclavia artery \\
\hline RV & Right ventricle \\
\hline TV & Tricuspid valve \\
\hline VCI & Inferior vena cava \\
\hline VCS & Superior vena cava \\
\hline \multicolumn{2}{|c|}{ Heart defects - pathomorphological terminology } \\
\hline AS & Aortic stenosis \\
\hline ASD & Atrial septum defect \\
\hline AoVS & Aortic valve stenosis \\
\hline AVSD & Atrioventricular septal defect \\
\hline CAVSD & Complete atrioventricular septal defect \\
\hline $\mathrm{CoA}$ & Coarctation of the aorta \\
\hline DORV & Double outlet right ventricle \\
\hline $\mathrm{EFE}$ & Endokardfibroelastosis \\
\hline HLH & Hypoplastic left heart \\
\hline $\mathrm{HRH}$ & Hypoplastic right heart \\
\hline IAA & Interrupted aortic arch \\
\hline PA & Pulmonary atresia \\
\hline $\mathrm{PaVA}$ & Pulmonary valve stenosis \\
\hline PS & Pulmonary stenosis \\
\hline TA & Tricuspid atresia \\
\hline TAC & Truncus arteriosus communis \\
\hline TAPVS/ TAPVD & $\begin{array}{l}\text { Total anomalous pulmonary venous } \\
\text { connection/drainage }\end{array}$ \\
\hline TGA & Transposition of the great arteries \\
\hline TOF & Tetralogy of Fallot \\
\hline VSD & Ventricular septal defect \\
\hline
\end{tabular}


hours: this was for the choice of images, the notation used in the images, compression of the images, insertion of them into the PowerPoint presentation, as well as the entry of the clinical data and the case request. The case data was sent as an email attachment ( 2 cases per week) to 5 experts in four different countries (Germany, England, Austria, the Netherlands).

\section{Results}

The number of images per case was between 3 and 7 . The size of the files was between 439 and $942 \mathrm{~kb}$ (Table 3 ). All of the 10 cardiac malformations were correctly diagnosed by all 5 experts. In 8 of the 10 cases at least one expert made a request for more information. Their requests were for further special cardiac findings which had not been included in the original request and for additional images of the pathological conditions which had not been easy to recognize on the images originally supplied (Table 4). The reasons for this were that individual pathological conditions were not recognized by the pathologist performing the autopsy or had been interpreted differently. After further transmission of text and images of the cases which could not be diagnosed fully based on the information conveyed originally, correct diagnoses were made in all instances. The participating experts found that the general information on the cases (age, body measurements, sex, condition of the samples, clinical findings, extra-cardial malformations, cytogenetic findings), the structure of the case presentation and the labeling of the images were adequate. In the central question of the applicability of digital transmission for difficult diagnoses all the experts found the quality of the images to be very good. A $17^{\prime \prime}$ monitor was found to be adequate for judging the overview image of the heart, but optimal was a $19^{\prime \prime}$ monitor. In contrast, the experts found that the images in several complicated cardiac malformations as well as overview images of certain heart segments were inadequate. The preparation of the cases for telepathology took on the average 1-2 hours. This included the compression of the heart images, which had already been saved during the autopsy in the findings documentation system, their copying into PowerPoint presentations as well as the entry of the text with the findings. Since fetal heart autopsies are quite time-consuming, the time spent for preparing the telepathological request was not significant, especially since no time is needed for the complicated packaging of the materials and the trip to the post office.

Obtaining a second opinion from an expert can enhance the quality of diagnoses of cardiac malformations since pathologists with insufficient experience in this special area run the risk of overlooking pathological conditions or of diagnosing them incorrectly. In addition correct assignment of findings to a complex heart malformation can be very difficult.

\section{Discussion}

In recent years telepathology has played an increasing role in routine work. In a large series of investigations Dunn [2] showed that telepathology can be used in routine work $[1,3-5,12]$.

Telepathology is used mostly today in histology. Macroscopy is only of importance within the context of frozen section diagnostics [4,6,7].

Table 3

Practicability: fastest reply, number of images, size of mail

\begin{tabular}{|c|c|c|c|c|c|}
\hline $\begin{array}{l}\text { Case } \\
\text { No. }\end{array}$ & Cardiovascular malformations & Rerequests & $\begin{array}{l}\text { Minimal tasks } \\
\text { reply (days) }\end{array}$ & $\begin{array}{c}\text { Number of } \\
\text { pictures }\end{array}$ & $\begin{array}{l}\text { Größe der Falldatei } \\
\text { in } \mathrm{kb} \text { (komprimiert) }\end{array}$ \\
\hline 1 & Interruption of aortic arch (“Type B”) & Yes & 1 & 4 & 572 \\
\hline 2 & $\begin{array}{l}\text { Common atrioventricular junction (Rastelli Type a), } \\
\text { defect within oval fossa (atrial septum defect II) }\end{array}$ & Yes & 1 & 5 & 845 \\
\hline 3 & Double outlet right ventricle & No & 1 & 6 & 942 \\
\hline 4 & Double outlet right ventricle & Yes & 2 & 3 & 616 \\
\hline 5 & Complete transposition of the great arteries & No & 1 & 4 & 603 \\
\hline 6 & Tetralogy of Fallot & Yes & 2 & 6 & 819 \\
\hline 7 & Complete transposition of the great arteries & No & 1 & 7 & 711 \\
\hline 8 & Hypoplastic left heart syndrome & No & 1 & 7 & 791 \\
\hline 9 & Hypoplastic left heart syndrome & Yes & 1 & 5 & 799 \\
\hline 10 & Aortic valve stenosis & No & 1 & 3 & 439 \\
\hline
\end{tabular}


Table 4

Detailed description of questions for clarification asked by the experts

\begin{tabular}{|c|c|c|c|}
\hline $\begin{array}{l}\text { Case } \\
\text { No. }\end{array}$ & Cardiovascular malformations & Call backs & $\begin{array}{l}\text { No. of additional } \\
\text { images }\end{array}$ \\
\hline 1 & Interruption of aortic arch ("Type B") & $\begin{array}{l}\text { How is the aortic valve? } \\
\text { How is the subaortic area? } \\
\text { How is the size of the LV? }\end{array}$ & 2 \\
\hline 2 & $\begin{array}{l}\text { Common atrioventricular junction (Rastelli Type a), } \\
\text { defect within oval fossa (atrial septum defect II) }\end{array}$ & $\begin{array}{l}\text { A problem is to determine the type of AVSD. } \\
\text { Is the aortic orifice connected to the LV or RV? }\end{array}$ & 2 \\
\hline 3 & Double outlet right ventricle & $\begin{array}{l}\text { Is the VSD perimembranous? } \\
\text { Is there downward displacement of tricuspid valve giving } \\
\text { Ebstein's malformation? }\end{array}$ & \\
\hline 4 & Double outlet right ventricle & $\begin{array}{l}\text { Difficult to be sure of precise degree of aortic override. } \\
\text { The mitral valve can not be seen in relation to the VSD. } \\
\text { The size of the LV compared to the RV can not be seen. }\end{array}$ & 3 \\
\hline 5 & Complete transposition of the great arteries & None & - \\
\hline 6 & Tetralogy of Fallot & $\begin{array}{l}\text { Is subpulmonary stenosis present? } \\
\text { Is overriding of the aorta present? }\end{array}$ & 2 \\
\hline 7 & Complete transposition of the great arteries & None & - \\
\hline 8 & Hypoplastic left heart syndrome & $\begin{array}{l}\text { Is there aortic coarctation at the isthmus? } \\
\text { The segmental analysis should mentioned the aortic atresia. }\end{array}$ & 2 \\
\hline 9 & Hypoplastic left heart syndrome & $\begin{array}{l}\text { What is state of atrial septum? } \\
\text { Is there aortic coarctation? }\end{array}$ & 1 \\
\hline 10 & Aortic valve stenosis & $\begin{array}{l}\text { Please check the origin of both coronary arteries. } \\
\text { How are the tricuspid and pulmonary valves? } \\
\text { How is the valvula foraminis ovalis? }\end{array}$ & 1 \\
\hline
\end{tabular}

In fetal pathology, however, macroscopy plays a decisive role. From the clinical perspective high demands are made on the diagnosis of malformations. Increasingly, autopsies have to be performed on fetuses from the early weeks of pregnancy $[10,11]$. There are few experts in this area in Germany who are available for consultation. One way of improving this situation is by means of telepathology. An essential difficulty in the presentation of macroscopic facts is anatomic assignation in detailed images. It is of importance, therefore, to present an effective and comprehensible case description to avoid misunderstandings in the interpretation of findings. These problems do not exist in histology when a second opinion is sought.

In the present study we have shown that, in principle, telepathology can be used to achieve an effective and reliable diagnosis in the case of congenital cardiac malformations and that the technique can be integrated into routine autoptic work. The large amount of time spent on preparation, presentation and description of the case is relativized by the fact that there are only a limited number of cases with complex cardiac malformations (about 30 a year). The average extra time of 1-
2 hours will be reduced when the PowerPoint presentations are replaced by an HTML version, which will be created directly at the workplace for fetal pathology with the electronic medical findings management system PIA (Professional Image Archiving, Viewpoint Bildverarbeitung GmbH, Gilching, Germany) we have been using since 1995 . Fetal autopsy satisfying modern, clinical requirements can be carried out in a focussed and effective manner using data processing methods [8,9].

By means of exact classification of rare cardiac malformations it is possible to develop a reference database. Further advantages which follow from the already existing digital case documentation are presentations for teaching and advanced training, for example, on CDs or over the World-Wide Web.

Telepathology makes it possible to establish contact with different experts regardless of their geographic location. This will provide a possibility in the future as well for satisfying the growing qualitative demands being made of fetal and child pathology given that there is only a limited number of experts in this area. 


\section{Acknowledgement}

We would like to thank the experts who participated in the present study, Prof. R. Anderson (Institute of Child Health, University College London, UK), Dr. Margot Bartelings (Dept. of Anatomy and Embryology, University Leiden, the Netherlands), Prof. N. Böhm (Institut für Pathologie der Universität Freiburg, Germany), Dr. med. Eva Karpf (Abteilung für Pädopathologie der Universität Graz, Austria), Prof. Ingeborg Röse (Institut für Pathologie der Universität Magdeburg, Germany), for their cooperation and useful comments in the diagnosis of the heart malformations in the current study.

\section{References}

[1] M. Dietel, T.N. Nguyen-Dobinsky and P. Hufnagl, The UICC Telepathology Consultation Center. International Union Against Cancer. A global approach to improving consultation for pathologists in cancer diagnosis, Cancer 89 (2000), 187191.

[2] B.E. Dunn, H. Choi, U.A. Almagro, D.L. Recla, E.A. Krupinski and R.S. Weinstein, Routine surgical telepathology in the Department of Veterans Affairs: experience-related improvements in pathologist performance in 2200 cases, Telemed. J. 5 (1999), 323-337.

[3] P. Hufnagl, T.N. Nguyen-Dobinsky, B. Stock, F. Fiedler and M. Dietel, Das Telepathologiesystem TPS 1 für RoutineTelepathologie, Pathol. Res. Pract. 196 (2000), 450.
[4] K. Kayser, M. Fritz and M. Drlicek, Aspects of telepathology in routinary work with specific emphasis on ISDN, Arch. Anat. Cytol. Pathol. 43 (1995), 216-218.

[5] K. Kayser, J. Szymas and R.S. Weinstein, Telepathology, Springer, Heidelberg, New York, 1999.

[6] M. Oberholzer, H.R. Fischer, H. Christen, S. Gerber, M. Bruhlmann, M.J. Mihatsch, T. Gahm, M. Famos, C. Winkler, P. Fehr et al., Telepathology: frozen section diagnosis at a distance, Virchows Arch. 426 (1995), 3-9.

[7] P. Schwarzmann, B. Binder, R. Klose and M. Kaeser, Histkom - evaluation of active telepathology in fieldtests, Adv. Clin. Pathol. 2 (1998), 135-138.

[8] C. Tennstedt, P. Hufnagl, T.N. Nguyen-Dobinsky, R. Chaoui, R. Bollmann, M. Urban, H. Körner, S. Tietz, P. Tietz and M. Dietel, Moderne, an klinischen Anforderungen orientierte Fetalautopsie unter Nutzung von informationstechnischen Methoden, Pathologe 6 (1997), 445-452.

[9] C. Tennstedt, K. Wehrstedt, M. Dietel, M. Vogel and P. Hufnagl, Use of telepathology in fetal diagnostics, Pathol. Res. Pract. 196 (2000), 442.

[10] C. Tennstedt, P. Hufnagl, R. Chaoui, H. Körner and M. Dietel, Fetal autopsy: Essential changes in the last few years, Eur. J. Obstet. Gyn. RB (2001) (in press).

[11] C. Tennstedt, P. Hufnagl, H. Körner, M. Vogel, M. Dietel and R. Chaoui, Fetal autopsy: the most important contribution of pathology in a center for perinatal medicine, Prenatal Diag. Ther. (2001) (in press).

[12] R.S. Weinstein, A.K. Bhattacharyya, A.R. Graham and J.R. Davis, Telepathology: a ten-year progress report, Hum. Pathol. 28 (1997), 1-7.

[13] K. Wehrstedt, C. Tennstedt and P. Hufnagl, Telepathology in fetal pathology, Elec. J. Pathol. Histol. 6(3) (2000), No. 00309. 


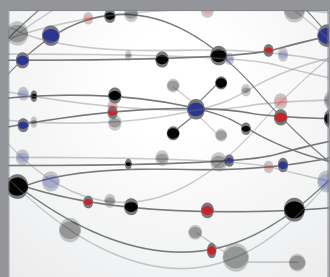

The Scientific World Journal
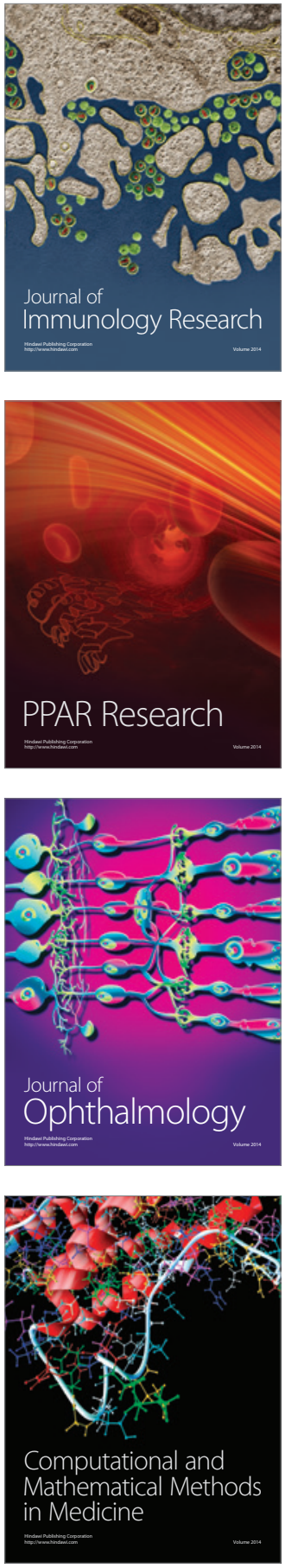

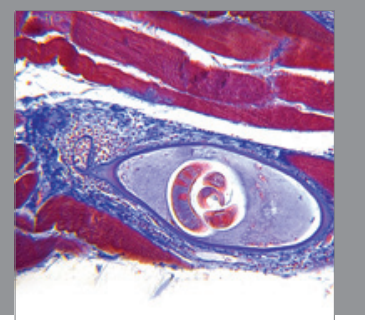

Gastroenterology

Research and Practice
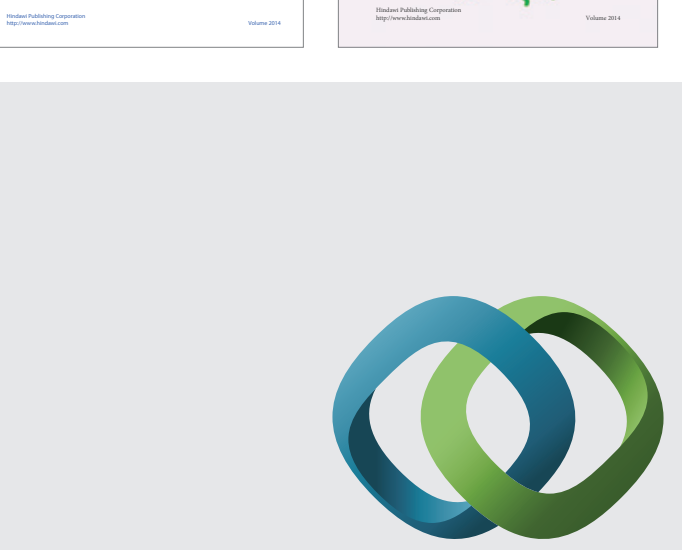

\section{Hindawi}

Submit your manuscripts at

http://www.hindawi.com
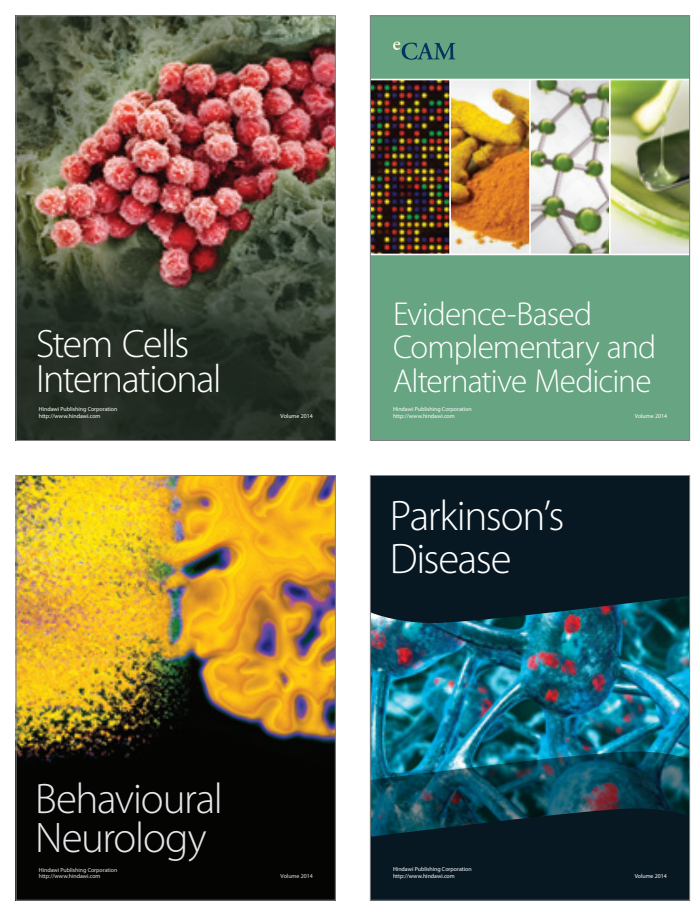

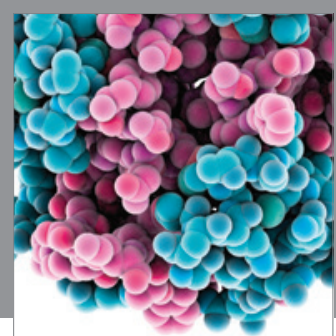

Journal of
Diabetes Research

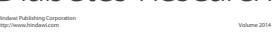

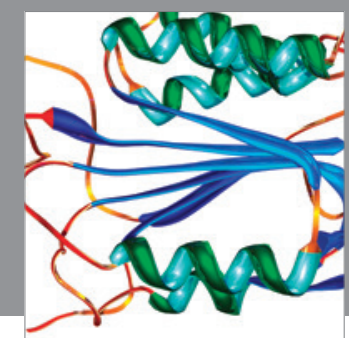

Disease Markers
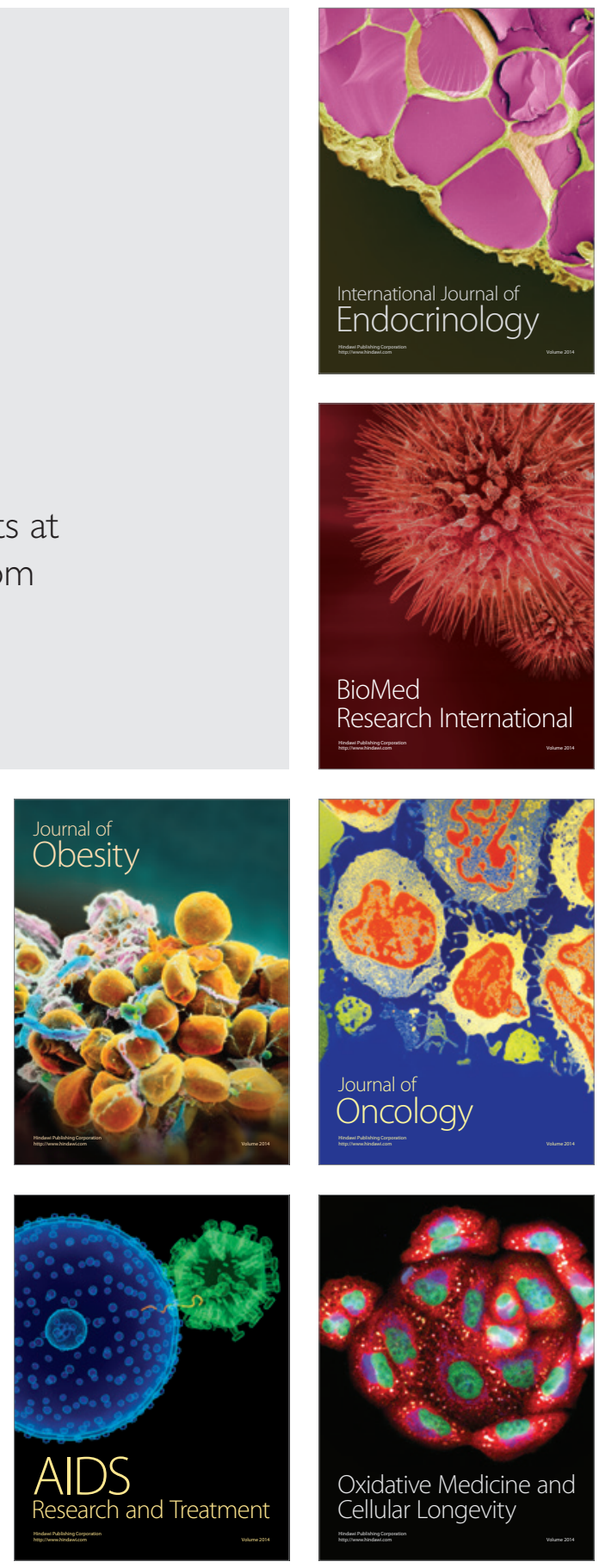